\title{
Cluster based Routing Schemes in Wireless Sensor Networks: A Comparative Study
}

\author{
Awanish Kumar Yadav \\ Department of computer science \\ and engineering \\ Krishna institute of engineering \\ and technology \\ Ghaziabad (U.P.), India.
}

\author{
Poonam Rana \\ Department of computer science \\ and engineering \\ Krishna institute of engineering \\ and technology \\ Ghaziabad (U.P.), India
}

\begin{abstract}
Recent improvements in the field of micro-electromechanical system, digital electronics and wireless communication technology are responsible for the development in applications of wireless sensor networks. Wireless sensor networks (WSNs) are consisting of large number of cheap and tiny devices known as sensor nodes. In WSNs, sensor nodes communicate to each other via the many communication approaches and these routing approaches are governed by routing protocols. These routing protocols are reliable for performance of wireless sensor networks. On the basis of these, this paper contains the survey on wireless sensor networks. Based on the network architecture, routing protocols in wireless sensor networks are categorized into three main types: data centric, cluster based or hierarchical routing and location based routing. Because of certain advantages clustering is becoming as an active root in routing technology. This paper cover the survey on cluster based routing in wireless sensor networks, summarize the merits and limitation of clustering protocols in wireless sensor networks, and suggest a classification of cluster based routing method. Finally conclude the paper.
\end{abstract}

\section{Keywords}

Clustering; Routing protocols; Wireless sensor networks; Cluster-based Routing, WSNs.

\section{INTRODUCTION}

The enhancement of wireless sensor network was formally motivated by military applications such as force protection, monitoring militant movement in remote area, battleground surveillance and opponent tracking. But these days, wireless sensor networks are used in many other application, including environmental observation, habitat monitoring, traffic control, home automation, and health application [1]. The WSN is collection of large number of the sensor nodes. The architecture diagram of sensor node is shown in figure 1. A node consists of mainly four units: a tiny sensor, a microprocessor, a power supply unit, a memory, and a radio receiver to communicate with the whole networks [2]. Because of the inherent limited energy resources, processing capacity and data transfer bandwidth, effective routing becomes a significant concern in wireless sensor networks. Routing schemes in WSNs are responsible for find out and preserving the energy efficient path. On the basis of network architecture, WSN schemes can be divided in to three categories: data centric cluster based or hierarchical and location based routing. Data-centric schemes are based on the query and naming of desirable data.

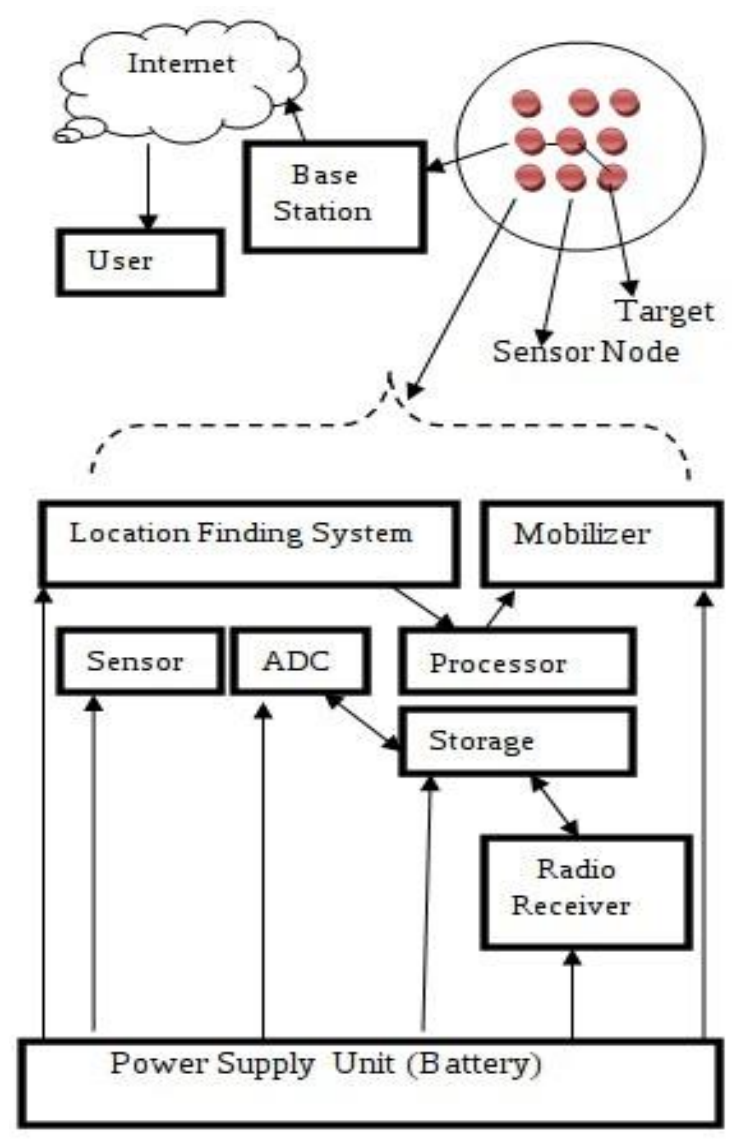

Fig.1. Architecture of sensor node in WSNs (source: [2])

Location-based schemes use the position information to transmit the data to the desirable regions instead the entire network. The routing procedures that are depend on networkflow framework, schemes that try for encounter some quality of service (QoS) requirements and routing function are categories as network flow, quality of service schemes. The main aim of cluster based schemes or hierarchical protocol is to make cluster of the sensor nodes that depend on the received signal strength. The transmission will only perform by such cluster heads than all sensor nodes, so this will save energy [3].

This paper provides a sufficient survey of several routing protocols proposed in recent years. The rest of paper is organized as follows. Section 2, explain the cluster based routing protocols. Section 3 compare the different routing protocols in cluster based routing. Sections 4 present the conclusion and future work. 


\section{CLUSTER BASED ROUTING PROTOCOLS IN WSNS}

In wireless sensor network, collection of sensor nodes into a cluster is well-known as clustering. Every cluster contains a leader called cluster head. A cluster head may be selected by the group of cluster. A cluster head collects the information from the nodes within cluster and send this information to the base station (destination). The clustering procedure in WSNs is shown in figure 2. Clustering can be used as an energyefficient communication protocol. The main aim of clustering is to minimize the total transmission power aggregated over the nodes in the selected path, and to balance the load between the nodes for extend the network lifetime. Cluster-based routing algorithms are growing to be an essential part of routing technology in wireless sensor networks on account of a form of advantages, such as larger scalability, less load, a smaller amount energy consumption and extra robustness [4].

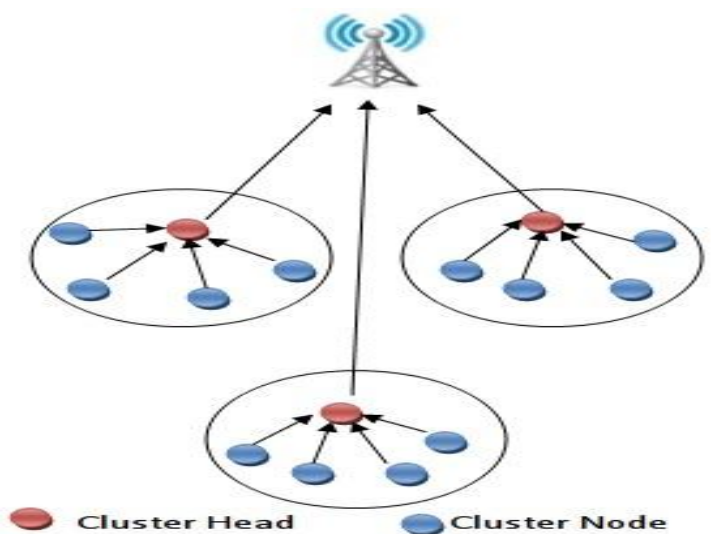

Fig.2. Clustering procedure in WSNs

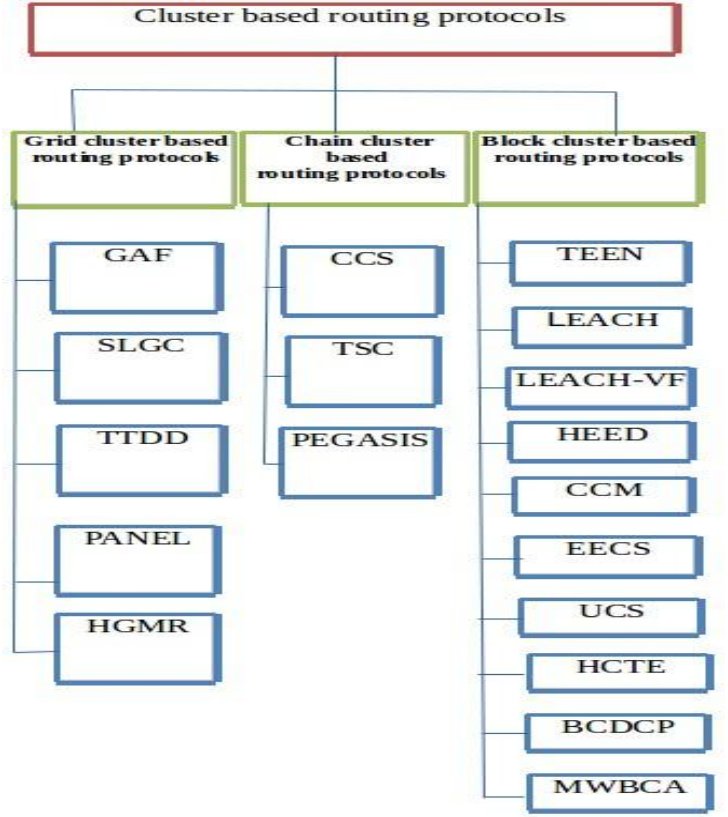

Fig.3. Classification of cluster based routing protocols in Wireless Sensor Networks

The cluster based routing protocol [2] are classified into three kinds: grid cluster based, chain cluster, and block cluster based routing protocols. The classification of cluster based routing protocols is shown in figure 3 . The standard grid cluster based routing protocols are GAF, SLGC, TTDD, PANEL, HGMR etc. The standard chain cluster based routing protocols are CCS, TSC, PEGASIS. The popular block cluster based routing protocols are TEEN, LEACH, LEACH-VF, HEED, CCM, EECS, UCS, HCTE, BCDCP, MWBCA etc. The advantages and drawbacks of the grid cluster based routing protocols, chain cluster based routing protocols, and block cluster based routing protocols are given in table1, table 2 and table 3. 
Table 1. Summary of advantages and drawbacks of grid cluster based routing protocols

\begin{tabular}{|c|c|c|c|}
\hline Protocols & & Advantages & Drawbacks \\
\hline GAF [5] & & $\begin{array}{l}\text { GAF is totally localized and statics } \\
\text { GAF can enhance the lifetime of the sensor network by } \\
\text { saving energy }\end{array}$ & $\begin{array}{l}\text { GAF can inject the traffic, } \\
\text { and the wait is not expected } \\
\text { and bounded. This things } \\
\text { create it inappropriate for } \\
\text { real-time situation in WSNs }\end{array}$ \\
\hline SLGC [6] & & $\begin{array}{l}\text { In SLGC schemes, energy utilization is minimum } \\
\text { SLGC schemes has a better efficiency level }\end{array}$ & $\begin{array}{l}\text { SLGC can incur extra } \\
\text { overhead in the situation of } \\
\text { complex data communication }\end{array}$ \\
\hline TTDD [7] & & $\begin{array}{l}\text { TTDD can determine and solve the multiple-mobile } \\
\text { sinks and sink-moving difficulty in major-scale WSNs. } \\
\text { TTDD is best applicable for event-detecting WSNs } \\
\text { with uneven, instead of constant data traffic }\end{array}$ & $\begin{array}{l}\text { TTDD has more latency } \\
\text { because the forwarding route } \\
\text { is not the smallest route. } \\
\text { Due to formation of grid } \\
\text { structure and query flooding, } \\
\text { TTDD have lower energy } \\
\text { efficiency }\end{array}$ \\
\hline PANEL [8] & & $\begin{array}{l}\text { PANEL maintains asynchronous applications } \\
\text { It is an energy-efficient method that guarantees long } \\
\text { network lifetime and load balancing because each node } \\
\text { turn into a cluster head with equal probability }\end{array}$ & $\begin{array}{l}\text { In this scheme, clusters are } \\
\text { pre-elected, which makes it } \\
\text { unsuitable to WSNs. } \\
\text { To find out geographic } \\
\text { position information, unique } \\
\text { conditions are needed, which } \\
\text { are not forever available and } \\
\text { which control the use of } \\
\text { PANEL in WSNs. }\end{array}$ \\
\hline HGMR [9] & & $\begin{array}{l}\text { Scalability problem does not occur in HGMR. } \\
\text { It has very simple membership management } \\
\text { It has energy efficient routing }\end{array}$ & $\begin{array}{l}>\text { The simple network } \\
\text { distribution may not get the } \\
\text { most favorable routing paths. } \\
>\quad \text { Energy utilization may be } \\
\text { disturbed because all } \\
\text { communication are to Access } \\
\text { Points } \\
>\quad \text { In this schemes, the } \\
\text { efficiency of routing path is } \\
\text { minimal }\end{array}$ \\
\hline
\end{tabular}

Table 2. Summary of advantages and drawbacks of chain cluster based routing protocols

\begin{tabular}{|c|c|c|}
\hline Protocols & Advantages & Drawbacks \\
\hline CCS [10] & $\begin{array}{l}\text { In CCS, energy consumption is decreases because the } \\
\text { length over which the message can be sending out to the } \\
\text { base station from the cluster head is narrowed } \\
\text { Conserves energy by separating the network into } \\
\text { concentric group }\end{array}$ & $\begin{array}{l}\text { Nodes be in touch with their } \\
\text { nearest neighbor by using } \\
\text { small radio capacity, however } \\
\text { the long chain is responsible } \\
\text { for large delays }\end{array}$ \\
\hline TSC [11] & $\begin{array}{l}\text { TSC minimize the unessential data transmission in the } \\
\text { sensor network }\end{array}$ & $\begin{array}{l}\text { TSC protocols may attains the } \\
\text { unbalanced utilization of } \\
\text { energy throughout the whole } \\
\text { networks }\end{array}$ \\
\hline $\begin{array}{l}\text { PEGASIS } \\
{[12]}\end{array}$ & $\begin{array}{l}\text { PEGASIS minimize the overhead because of dynamic } \\
\text { cluster formation } \\
\text { Minimize the number of data transmissions because of the } \\
\text { chain of data aggregation. } \\
>\quad \text { In the PEGASIs, load of energy is distributed equivalently } \\
\text { in the network }\end{array}$ & $\begin{array}{l}\text { PEGASIS is not right choice } \\
\text { for networks with time- } \\
\text { irregular topologies } \\
\text { Communication has time- } \\
\text { consuming delays, which can } \\
\text { cause restricted access of node }\end{array}$ \\
\hline
\end{tabular}


Table 3. Summary of advantages and drawbacks of block cluster based routing protocols

\begin{tabular}{|c|c|c|}
\hline Protocols & Advantages & Drawbacks \\
\hline TEEN [13] & $\begin{array}{l}\text { TEEN is well appropriate to time-critical applications } \\
\text { It performs well in the situation like rapid changes in he } \\
\text { sensed attributes such as temperature }\end{array}$ & $\begin{array}{l}\text { At any time if the thresholds } \\
\text { are not encounter, the node } \\
\text { will not communicate, and if } \\
\text { the node dies, the network will } \\
\text { not capable to find it }\end{array}$ \\
\hline LEACH [14] & $\begin{array}{l}\text { LEACH keep away from lot of energy excess } \\
\text { LEACH make use of Time Division Multiple Access, it } \\
\text { maintains cluster heads from unnecessary collisions }\end{array}$ & $\begin{array}{l}\text { It is not appropriate to } \\
\text { networks deployed in large } \\
\text { regions }\end{array}$ \\
\hline $\begin{array}{l}\text { LEACH-VF } \\
{[15]}\end{array}$ & $\begin{array}{l}>\quad \text { It solves the problem of areas by way of overlapped } \\
\text { sensing coverage } \\
>\quad \text { It solves the difficulty of sensing holes }\end{array}$ & $\begin{array}{l}\text { Energy efficiency in LEACH- } \\
\text { VF is very poor }\end{array}$ \\
\hline HEED [16] & $\begin{array}{l}>\text { HEED is a fully distributed cluster-based routing } \\
\text { protocols } \\
>\quad \text { HEED attains scalability and high energy efficiency by } \\
\text { communicating in a multi-hop fashion }\end{array}$ & $\begin{array}{l}\text { Energy consumption is not } \\
\text { balanced }\end{array}, \begin{array}{l}\text { Huge overhead is formed } \\
\text { because of multiple rounds. }\end{array}$ \\
\hline CCM [1] & $\begin{array}{l}>\text { Cluster part have minimum delay } \\
>\text { In CCM, Overhead on the network is low }\end{array}$ & $\begin{array}{l}\text { Cluster part preserves more } \\
\text { energy } \\
\text { CCM scheme uses only } \\
\text { residual energy to selects the } \\
\text { cluster head }\end{array}$ \\
\hline EECS [1] & $\begin{array}{l}>\quad \text { EECS builds a more balanced network in conditions of } \\
\text { communication load and energy consumption } \\
>\quad \text { EECS uses dynamic sizing of clusters, to communicate } \\
\text { with long distances with base station }\end{array}$ & $\begin{array}{l}\text { EECS is based on the uses of } \\
\text { global information for } \\
\text { communication which causes } \\
\text { the lot of overhead }\end{array}$ \\
\hline UCS [1] & $>\quad$ UCS schemes has minimum energy utilization & $\begin{array}{l}\text { UCS is still not sufficient for } \\
\text { large-range networks }\end{array}$ \\
\hline HCTE [17] & $>$ HCTE avoids unbalanced energy consumption. & $\begin{array}{l}\text { Energy efficiency in HCTE is } \\
\text { very poor }\end{array}$ \\
\hline BCDCP [18] & $\begin{array}{l}>\text { BCPCP saves energy and time } \\
>\quad \text { Cluster-head distribution difficulty doesn't exist }\end{array}$ & $\begin{array}{l}\text { BCDCP is not appropriate for } \\
\text { large networks and reactive } \\
\text { networks }\end{array}$ \\
\hline MWBCA [19] & $>$ Energy consumption in MWBCA is balanced & $\begin{array}{l}\text { Scalability of MWBCA is very } \\
\text { poor }\end{array}$ \\
\hline
\end{tabular}

\section{COMPARISON OF CLUSTERING PROTOCOLS}

Table 4. Comparison of the presented clustering protocols

\begin{tabular}{|l|c|c|c|c|c|c|}
\hline Protocols & Scalability & $\begin{array}{l}\text { Load } \\
\text { Balancing }\end{array}$ & $\begin{array}{l}\text { Energy } \\
\text { Efficiency }\end{array}$ & $\begin{array}{l}\text { Algorithm } \\
\text { Complexity }\end{array}$ & $\begin{array}{l}\text { Cluster } \\
\text { Stability }\end{array}$ & $\begin{array}{l}\text { Delivery } \\
\text { Delay }\end{array}$ \\
\hline GAF & High & Moderate & Moderate & Moderate & Moderate & Poor \\
\hline SLGC & Very poor & Moderate & Moderate & Moderate & Moderate & Very small \\
\hline TTDD & Poor & Good & Very poor & Low & Very high & Very large \\
\hline PANEL & Poor & Good & Moderate & High & Poor & Moderate \\
\hline HGMR & Very high & Poor & Poor & Low & High & Moderate \\
\hline CCS & Poor & Very poor & Poor & Moderate & Poor & Large \\
\hline TSC & Moderate & Poor & Moderate & Moderate & Moderate & Moderate \\
\hline PEGASIS & Moderate & Very poor & Poor & High & Poor & Very large \\
\hline TEEN & Poor & Good & Very high & High & High & Small \\
\hline LEACH & Very poor & Moderate & Very poor & Low & Moderate & Very small \\
\hline LEACH-VF & Very poor & Moderate & Moderate & Moderate & High & Very small \\
\hline
\end{tabular}




\begin{tabular}{|l|c|c|c|c|c|c|}
\hline HEED & Moderate & Moderate & Moderate & Moderate & High & Moderate \\
\hline CCM & Very poor & Moderate & Very poor & Moderate & High & Small \\
\hline EECS & Poor & Moderate & Moderate & Very high & High & Small \\
\hline UCS & Poor & Poor & Very poor & Moderate & High & Small \\
\hline HCTE & Very poor & High & Very poor & Moderate & Moderate & Very small \\
\hline BCDCP & Very poor & Good & Very poor & Very high & High & Small \\
\hline MWBCA & Very poor & High & Moderate & Moderate & Moderate & Very small \\
\hline
\end{tabular}

\section{CONCLUSION AND FUTURE WORK}

Wireless sensor networks (WSNs) have focused major attention over the previous few years. An emergent list of military and civil applications can provide work for WSNs for increased efficiency particularly in remote and hostile areas. Examples include disaster management, monitoring militant movement in remote area, enemy tracking, battleground observation, and border security. For these applications a large number of sensors are predictable. Formation of sensor nodes into clusters has been the good method for sustain scalability in WSNs. this paper survey the current position of the research and contains classification the different techniques. And also focus on the advantages and drawbacks of different cluster based routing protocols and signify them into tabular form. Based on comparison between different methods, it is clear that cluster based routing schemes are very efficient in performance growth of WSNs. This survey paper will be very helpful for researchers that are concerned about the improvement, modification or optimization of routing schemes for wireless sensor networks.

Energy consumption is one of the most important research areas of WSNs. It is requirement of WSNs to propose location based protocols which consume smallest amount of energy and provide high throughput. In future a protocol that has minimum energy consumptions can be proposed and implement. It is still an open problem that how to make cluster formation in heterogeneous sensor networks. Fault tolerance, security, cluster coverage, multi-hierarchy, and node placement are still open questions.

\section{ACKNOWLEDGMENT}

The authors would like to acknowledge the Department of Compute Science and Engineering, KIET, UPTU lucknow, for the facilities provided during this research.

\section{REFERENCES}

[1] Gulbadan Sikander et al., "A Survey of Cluster-based Routing Schemes for Wireless Sensor Networks", Smart Computing Review, vol. 3, no. 4, August 2013.

[2] Santar Pal Singh, S.C. Sharma, "A Survey on Cluster Based Routing Protocols in Wireless Sensor Networks", in Proc. Of International Conference on Advanced Computer Technologies and Applications (ICACTA2015), ELSEVIER, Procedia Computer Science 45 (2015) 687-695.

[3] Kemal Akkaya , Mohamed Younis, “A survey on routing protocols for wireless sensor networks", ELSEVIER, Ad Hoc Networks 3 (2005) 325-349.

[4] X. Liu and J. Shi, "Clustering Routing Algorithms In Wireless Sensor Networks: An Overview," KSII
Transactions on Internet and Information Systems, vol. 6 , no. 7, pp. 1735-1755, 2012.

[5] Y. Xu, J. Heidemann, and D. Estrin, "Geographyinformed Energy Conservation for Ad Hoc Routing," in Proc. of the 7th annual international conference on Mobile computing and networking, 2001, pp. 70-84.

[6] A. G. Delavar, S. Shamsi, N. Mirkazemi, and J. Artin, "SLGC: A New Cluster Routing Algorithm in Wireless Sensor Network for Decrease Energy Consumption," International Journal of Computer Science, Engineering and Application, vol. 2, no. 3, pp. 39-51, 2012.

[7] H. Luo, F. Ye, J. Cheng, S. Lu, and L. Zhang, “TTDD: Two-Tier Data Dissemination in Large-Scale Wireless Sensor Networks," Wireless Networks, vol. 11, no. 1-2, pp. 161-175, 2005.

[8] L. Buttyan and P. Schaffer, "PANEL: Position-based Aggregator Node Election in Wireless Sensor Networks," in Proc. of IEEE Internatonal Conference on Mobile Adhoc and Sensor Systems, pp. 1-9, 2007.

[9] D. Koutsonikolas, S. Das, Y. C. Hu, and I. Stojmenovic, "Hierarchical Geographic Multicast Routing for Wireless Sensor Networks," in Proc. of International Conference on Sensor Technologies and Applications, pp. 347-354, 2007.

[10] S. Jung, Y. Han, and T. Chung, "The Concentric Clustering Scheme for Efficient Energy Consumption in the PEGASIS," in Proc. of 9th International conference on Advanced Communication Technology, pp. 260-265, 2007.

[11] N. Gautam, W. Il Lee, and J. Y. Pyun, "Track-Sector Clustering for Energy Efficient Routing in Wireless Sensor Networks," in Proc. of $9^{\text {th }}$ IEEE International Conference on Computer and Information Technology, pp. 116-121, 2009.

[12] S. Lindsey, C. Raghavendra, and K. M. Sivalingam, "Data Gathering Algorithms in Sensor Networks Using Energy Metrics," IEEE Transactions on Parallel and Distributed Systems, vol. 13, no. 9, pp. 924-935, 2002.

[13] A. Manjeshwar and D. P. Agrawal, "TEEN: A Routing Protocol for Enhanced Efficiency in Wireless Sensor Networks," in Proc. of 15th International Parallel and Distributed Processing Symposium, pp. 2009-2015.

[14] W. R. Heinzelman, A. Chandrakasan, and H. Balakrishnan, "Energy-Efficient Communication Protocol for Wireless Microsensor Networks," in Proc. of 33rd Hawaii International Conference on System Sciences, pp. 1-10, 2000. 
[15] F. Awad,"Energy-Efficient and Coverage-Aware Clustering in Wireless Sensor Networks," Wireless Engineering and Technology, vol. 03, no. 03, pp. 142151, 2012.

[16] O. Younis and S. Fahmy, "HEED: A Hybrid, EnergyEfficient, Distributed Clustering Approach for Ad-hoc Sensor Networks," IEEE Transactions on Mobile Computing, vol. 3, no. 4, pp. 366-379, 2004.

[17] N. Azizi, J. Karimpour, and F. Seifi, "HCTE: Hierarchical Clustering based routing algorithm with applying the Two cluster heads in each cluster for
Energy balancing in WSN," IJCSI International Journal of Computer Science, vol. 9, no. 1, pp. 57-61, 2012.

[18] S. D. Muruganathan, R. I. Bhasin, and A. O. Fapojuwo, "A Centralized Energy-Efficient Routing Protocol for Wireless Sensor Networks," IEEE Communications Magazine, vol. 43, no. 3, pp. S8-13, 2005.

[19] Z. Fan and Z. Jin,“A Multi-weight Based Clustering Algorithm for Wireless Sensor Networks," College of Computer Science \& Educational Software Guangzhou University,2012. 